\title{
Rethinking the Business Model in Construction by the Use of Off-Site System Deliverance: Case of the Shaft Project
}

\author{
Thuesen, Christian; Hvam, Lars
}

Published in:

Journal of Architectural Engineering

Link to article, DOI:

10.1061/(ASCE)AE.1943-5568.0000095

Publication date:

2013

Link back to DTU Orbit

Citation (APA):

Thuesen, C., \& Hvam, L. (2013). Rethinking the Business Model in Construction by the Use of Off-Site System Deliverance: Case of the Shaft Project. Journal of Architectural Engineering, 19(4), 279-287.

https://doi.org/10.1061/(ASCE)AE.1943-5568.0000095

\section{General rights}

Copyright and moral rights for the publications made accessible in the public portal are retained by the authors and/or other copyright owners and it is a condition of accessing publications that users recognise and abide by the legal requirements associated with these rights.

- Users may download and print one copy of any publication from the public portal for the purpose of private study or research.

- You may not further distribute the material or use it for any profit-making activity or commercial gain

- You may freely distribute the URL identifying the publication in the public portal 


\section{RETHINKING THE BUSINESS MODEL IN}

\section{CONSTRUCTION BY THE USE OF OFF-SITE-}

\section{"SYSTEM DELIVERANCE" - THE SHAFT PROJECT}

\section{Christian Thuesen}

Technical University of Denmark, Department of Management Engineering, Produktionstorvet, Building 424, 2800 Lyngby, Denmark, chth@dtu.dk

\section{Lars Hvam}

Technical University of Denmark, Department of Management Engineering, Produktionstorvet, Building 426, 2800 Lyngby, Denmark, lahv@dtu.dk

Abstract 
This paper presents a set of insights to be used in the development of business models for off-site system deliveries contributing to the development of Off-Site Manufacturing practices (OSM). The theoretical offset for discussing the development of business models is the blue ocean strategy literature combined with theories on mass-customization and platform development identifying the optimization of cost and value through the handling of complexity as the central process. This framework is developed in order to analyze a specific case on system deliverances - the prefabrication of installation shafts. Findings from the development and production of the installation shaft show that system deliveries represent a promising strategy for moving from red ocean competitive environment with the predominant cost+ business model, to a blue ocean situation in which the competition emerges in the constant pursue of value creation and cost reduction. On the basis of that system deliverances represent a promising strategy in the future development and application of off-site manufacturing practices. The application of system deliveries is however demanding as it represents a fundamental shift in the existing design and production practices. More specifically the development of system deliveries requires: (1) an explicit market focus, enabling the achievement of economy of scale, (2) a coordinated and coherent development around the system deliverance focusing on its internal and external modularity. (3) development of processes and configuration practices which make it possible to put together (configure) the product matching the needs of the individual building project. (4) development of alliances between companies in enabling value chain integration.

Keywords: Business Models, OSM, Mass Customization, System Deliveries, Strategy, Modularization 


\section{INTRODUCTION}

The construction industry is often criticized for its inefficiency compared to other industries, its inability to innovate, to improve its practices and to provide value for its clients (Egan 1998). As a symptom of this fundamental challenge has the construction cost in Denmark increased by approx. 4,6 \% per year during the last 20 years (DS 2010)

Despite the increasing costs the companies are in the centre of the value chain struggling with making profit. As an example, large contractors in the Scandinavian countries are having an average EBIT between 0-3\% (Thuesen 2010). These very small margins compared to the cash flow make construction businesses vulnerable to changes in price levels and market development and consequently construction companies often are characterised by a low level of invested capital in production facilities.

The existing production regime in construction is heavily influenced by realizing one of kind projects. Thuesen et al (2009) argues this according to an often celebrated sectorial myth viewing buildings as unique. Today’s predominant view of buildings as unique - implies that:

1. the nature of the construction processes is chaotic

2. the buildings are realized through on-site production rather than off-site production

3. project management is the fundamental management principle

4. the inter-organisational cooperation is temporary

These characteristics of the building process are also mirrored in the in the physical product. Today's buildings are getting increasingly complex, manufactures of building 
parts are constantly pushing new technologies on the market which need to be integrated and optimized in each physical building. Consequently construction today is a mixture of new materials, processes, solutions and architectural visions - realized through a specific division of labour and institutionalized roles such as manufacturers of the basic parts, building companies (including craftsmen), engineering companies and architects. Under this existing regime, the value chain has become increasingly fragmented. This development has resulted in that most businesses operate from a cost + model, making the companies compete on their overhead rather than their core processes (Nicolini et al 2001 and Holti et al 2002). In this sense the marketplace is characterised as a typical red ocean environment - as described by Kim and Mauborgne (2004, 81):

Insert Table 1 about here

Although the red ocean market puts pressure on margins in each company by making them fight for survival, it also represents an opportunity for creating an uncontested market space pursuing a blue ocean strategy.

One of the strategies for escaping the red ocean market has been to develop Off Site Manufacturing practices (OSM) - a development which is discussed and supported through initiatives as Manubuild (Eichert and Kazi, 2007 and Kazi et al., 2009) and reflected upon in the special issue (Arif, 2009).

A wide range of cases studies have been undertaken to explore the benefits and challenges of OSM. Gibb (2001) discusses 5 historical and present casestudies covering a wide range of building constructs and most recently Buildoffsite (2010) presented 189 cameo case studies across all sectors of construction from residential 
through to civil and commercial. However given the growing interesting in the application of industrialized production methods the underlying business models of OSM practices like system deliveries has not been analyzed.

\section{AIM}

The ambition of this paper is to shed light on how new business models, in construction based on off-site system deliveries, can be developed, with the results of radical value increments for the users, companies and the society as a whole.

\section{THEORITICAL FRAMEWORK}

Theoretically the paper is based on two theoretical frameworks - one focusing on business model development and one on the principles of system deliverances.

\section{PRINCIPLES OF BUSINESS MODEL DEVELOPMENT}

According to (Johnson, Christensen, \& Kagermann, 2008) have very little formal studies been undertaken into the dynamics and processes of the development of business models.

Derived from the idea of escaping from red ocean markets (Kim and Mauborgne 2004) states "a blue ocean is created in the region where a company's actions favorably affect both its cost structure and its value proposition to buyers. Cost savings are made from eliminating and reducing the factors an industry competes on. Buyer value is lifted by raising and creating elements the industry has never offered before. Over time, costs are reduced further as scale economies kick in, due to the high sales volumes that superior value generates.” (Kim and Mauborgne 2004, 83) 
The fundamental business model behind this tradition is in other words the simultaneous pursuit of value creation and cost reduction. This principle is also found in other managerial traditions as for instance the lean thinking (e.g. Womack and Jones, 2003). Thus (Jørgensen, 2006) in an extensive literature study are concluding that "Elimination/reduction of waste and a focus on (end) customer value ... appear to be the most common features of the many different interpretations of [lean strategies]" While the application of lean in "Mass Production" environments (lean production) originally focuses on approaches, tools and methods through which waste is minimized while end-user value is maximized and continuous performance improvements can be achieved, it is build on the premises that the products remains stable while the processes is continuously improved (Pine 1993). Compared to this is the application Lean in the prevailing "individual customization” paradigm in construction (Lean Construction) focusing on developing tools and practices which support the tailoring of unique buildings to each customer (Thuesen et al 2009).

The separation of customer value and production cost is also central in Mass Customization strategies. But unlike the application of Lean in "Mass Production" environments (Lean Production) Mass Customization aim at producing flexible products/projects while at the same time leveraging economy of scale by standardization across products/project. Tseng and Jiao (2001) defines Mass Customization as "...producing goods and services to meet individual customer's needs with near mass production efficiency" (p. 685).

Thuesen et al. (2009) illustrates in the conceptual figure 1 how the separation of customer value and production cost is organized in different production paradigms like Mass Production, Mass Customization, and Individual Customization. 
Insert Figure 1 about here

The figure illustrates how customization and low cost traditionally have been perceived as mutually exclusive. You can either adopt a Mass Production strategy providing low cost but at the expense of uniformity and value creation or you can adopt an "Individual Customization” strategy creating high value delivering unique projects but failing to control complexity and thereby keeping the cost down and making the business more vulnerable. Mass customization tries to bridge these two strategies delivering customized products/projects while keeping cost down by controlling complexity (Schöning, 2007).

The development of robust business models is in other words a matter of managing complexity. Here the challenge is to have as large variety as required but as little variety as possible.

\section{PRINCIPLES OF SYSTEM DELIVERANCES}

System deliverances are examples of Mass Customization strategies (Pine 1993, Tseng \& Piller 2003, Salvador et al. 2009) realized in physical product systems. Overall can the use of system deliveries be thought of as a systematization and form of work preparation for both product and business processes. By systematically developing the company's business processes based on a module-based product range (Meyer and Lehnerd 1997) and the use of configuration systems (Hvam et al. 2008, Salvador and Forza 2002), it is possible to develop business processes for sales, production, installation and after sales service which have a much higher performance than today with respect to quality, throughput time, productivity and predictability. Sales take place by configuration of known modules/solution concepts into a complete 
solution adapted to the customer, instead of the current practice of planning from case to case, based on experience from previous projects. In this way it is already possible to create products/solutions which are well-defined in relation to the subsequent processes of production, installation and after sales service, in the sales phase. This means that much more robust and efficient business processes for production, installation and after sales service can be developed, based on well-defined and module-based products or solution concepts.

The basic principles of modularization and configuration is to develop modules which have a number of common characteristics in relation to the company's internal work procedures - such as design/customer adaptation, production, assembly and installation - and which at the same time can be varied, so they can fulfil the needs of the customer. In this connection, the big challenge is to develop modules which can be varied in relation to the parameters which the customer thinks are especially important and which provide value the customer value. As an example, we may mention that automobile factories try to standardize all parts which are "hidden" and which have no particular significance for the customer, whereas they try to create possibilities for variation in those parts which are visible and important for the customer's evaluation of the value of the vehicle.

Mikkelsen et al (2005) identifies two different strategies for developing system deliverances- a bottom-up and top-down approach as illustrated in the following figure.

Insert Figure 2 about here 
One direction (bottom up) shows the building material producers' development of system products, while the opposite direction (top down) show the development of building concepts - or concepts for parts of buildings.

In the "bottom up” process, producers of building components such as electric installations, wall elements, ceiling elements, wet rooms, roof constructions etc. develop their products in the direction of more complex system products. Compared to this the "top down" strategy focuses on developing concepts or platforms for types of buildings - for example, office buildings, factory buildings or particular types of housing.

Broadening the scope figure 3 shows how it is possible to adopt different design and production strategies by dividing activities into general and specific product/project development activities.

Insert Figure 3 about here

CTO means Configure to Order, i.e. a process in which a system product is configured based on the modules which are specified in the configuration system. ITO means Integrate to Order, i.e. a process in which a system product is put together, also using components from third party suppliers, which are not specified in the configuration systems. ETO means Engineer to Order, i.e. a process in which special solutions have to be developed for the customer (Hvam, 2006).

The concept of system delivery corresponds to the two middle possibilities, which differ slightly from one another. When the starting point is the basic product structure, the adaptation can have the character of adaptation engineering. When the starting point is components and modules, the adaptation has the character of configuration. 


\section{METHOD}

As the paper only analyzes one case, the ambition is not to make classical quantitative study. The ambition is to develop qualitative insights from this particular case (Yin, 2002) - raising key learning points, which subsequently can be subject to more detailed quantitative and qualitative analysis.

The paper draws upon existing studies of the installation shaft case (Vind \& Thomassen 2008 and Beim et al 2009) combined with a further collection of empirical material. The collection of empirical material consists of observations from development meetings coupled with semi-structured interviews (Kvale, 1996) of persons in relevant parts of the organisation from craftsmen to site engineers to directors. The interviews have been supplemented with internal documentation such as presentations, reports, drawings, sales material and calculations.

The outcomes of the observations, interviews and documentation were triangulated and the findings are reported below.

\section{CASE}

Installation shafts are an exemplary case on the development of construction products and practices as illustrated in figure 4 . Back in the 60' \& 70’ installation shafts were mass produced just like the prefabricated concrete elements for the structural part of the building.

But from the 80' and onwards the shafts have got increasingly complex, and contains a lot of new features. Consequently an average installation shaft consists of around ca. 300 operations among 9-10 technical crafts, done on 0,6 * 0,8 m with one-sided access and impossibly working conditions (NCC 2008) 
Insert Figure 4 about here

Thus the installation shafts are illustrating the contractor's lack of ability to control the complexity of the construction process. Although everyone has a share in the design and production of the shaft nobody takes full responsibility for the realization of the shaft and as a consequence the contractors end up with all the risk.

Based on the problems of producing individually customized shafts, NCC decided to develop a flexible shaft based on the ideas of system deliverances. The formal ambitions were to achieve (Vind and Thomassen 2008, 206):

1. more assemblage, less traditional crafts

2. higher degree of industrialization

3. robust budgets

The idea of the developed solutions is that all vertical installations of the main routes are concentrated in a shaft, which is split horizontally into factory produced units corresponding to each floor. The units are produced off-site in an industrial process and transported to the building site in order to be installed concurrently with the erection of the base building/main structure as illustrated in the following figure (Beim et al 2009).

Insert Figure 5 about here

The project was initiated in august 2006 as a part of a private funded innovation initiative in Denmark called “Byggeriets Innovation”. In the summer 2009 the first 
shaft was erected as a part of a construction project which encompassed both traditional and prefabricated shafts. The preliminary experiences are

1. great reduction in assembly time from 3 weeks to 7 minutes for each module a visible advantage of major importance for the communication and implementation of the project

2. the assembly of the shaft by the concrete worker works particular well significantly reducing the number of crafts involved during the onsite production.

3. the in situ pouring of concrete after the assemblage results in tight slap - an effect which usually has been impossible to achieve with the traditional construction method.

4. buy-in from the project workers, making the further implementation less challenging.

5. although the project is a success it suffers from the general slowdown in the construction industry.

\section{ANALYSIS}

We will in the following show how the concept of the shaft was designed in order to create customer value and reduce production costs

\section{CUSTOMER VALUE - VALUE PROPOSITIONS}

The premise for defining the customer value is the definition of which customers who should be targeted with the concept. Prior and during the development of the shaft the construction market was in an upturn characterized be high growths in prices on flats 
and massive investments by developers in big housing projects within the large cities. Consequently was the shaft targeted the market for multifamily houses (apartments). The value propositions for addressing this market were identified, by the use of a value canvas inspired from the blue ocean strategy (Figure 6).

Insert Figure 6 about here

By juxtaposing traditional shaft construction practices with a possible industrialized solution the project team indentified the value propositions they would build into the shaft. (Vind \& Thomassen 2008)

Here it was identified that the industrialized produced shaft would be superior to the traditional produced shaft, in terms of construction costs, cost of usage, aesthetics, construction time, ability to deliver, improved working conditions and quality.

\section{COST OPTIMIZATION}

The reduction of cost was based on three elements (1) the reduction of complexity through standardization and modularization, (2) expanding the window of purchasing and (3) off-site manufacturing.

\section{Complexity reduction through standardization and modularization}

The complexity of the shaft was handled in the development process by modelling a Product Variant Master (PVM). The basic idea of PVMs is to enable companies to describe and analyze their product portfolio and platform from different perspectives thus making it possible to optimise the relationship between customer value and production costs (Hvam et al 2008). 
Based on the PVM the shaft was defined as a compilation of modules with parametric rules for their placement. The modules are defined by their function as chassis, water, heating, ventilation, electrical and waste.

The modularization of the shaft should avoid over engineering for the design of the shaft while at the same time make it possible to reduce the number of variants and thereby being able to purchase larger batches of components - leveraging economy of scale.

An example of this reduction is illustrated the following figure of pipes

Insert Figure 7 about here

Traditional piping represents a huge variation of materials and dimensions. By modularizing and standardizing a few was chosen - giving great savings in fittings. The actual pipe is chosen from a table, governed by number of apartments and their size.

Expanding the window for purchasing

Besides the reduction of complexity, the cost was also reduced by the expansion of the window for procurement.

In traditional construction practices the design of the shaft is finalized as one of the last elements of the building - if it is finalized at all and not just left to the local decisions on the construction site. Consequently the cost of materials which go into the on-site production of the shaft is defined very late and it might only be supplied by nearby wholesalers.

By defining the design through configuration the window for procurement is extended as illustrated in the figure below. 
Insert Figure 8 about here

The wider window for procurement makes it possible to move the production from DK to other countries where the wages and material prices are lower. The initial production of the shaft was thus produced in DK in order to develop a solution before the production was outsourced. However today there exist agreements for moving the production to one or more east European countries.

\section{Prefabrication and assemblage}

The final and properly the most significant strategy for keeping the cost down is the use of prefabrication and assemble as illustrated in the figure below.

Insert Figure 9 about here

By letting concrete workers assemble the shaft with the rest of the building the on-site workforce is significantly reduced. Thus the assembly time has been reduced dramatically enabling a more optimal production flow in the rest of the construction project. Finally do the standardized and controlled production result in a more consistent quality.

\section{DISCUSSION}

We will now discuss the principles of developing new business models in construction based on system deliverances, but first we will juxtapose the system deliverances with the existing production paradigm in construction. 


\section{SYSTEM DELIVERANCES VS. EXISTING CONSTRUCTION PRACTICES}

In the following table, we summarize a number of the differences between traditional building practices and construction based on the use of system deliveries. The table describes which targets/changes which is tried to get achieved by using system deliveries, in relation to the current situation in the building industry.

Insert Table 2 about here

The characteristics of system deliveries can be summarized as follows: System products are characterized by being more integrated, multifunctional and with welldefined interfaces. For the complete building process this means that work can take place in a much more industrial manner, than the situation is today. A natural consequence of industrialization is a series of gains in the form of a reduction of throughput time, achievement of much better precision in delivery, better quality, productivity, increased innovation and a greater ability to efficiently fulfil the needs of the individual customer as illustrated in the shaft case.

By developing, marketing and producing a system deliverance, such as the installation shaft, it becomes easier and quicker to assemble the product and its associated installations on the building site. You get a product with correct production quality, faster delivery and at lower cost, which possibly gives a lower price for the buyer. In addition there will be fewer actors on the building site. The task of coordination and adaptation on the building site is markedly reduced.

\section{BUSINESS MODELS BASED ON SYSTEM DELIVERANCES}

As illustrated in table 2 there are considerably differences between system deliveries and traditional construction practices as for instance the rethinking of the design and 
construction process by the use of configuration - separating development from the production.

On a generic level the development of system deliverances can be interpreted as a movement towards Mass Customization. A movement which is focusing on leveraging similarity, while keeping the needed flexibility towards the market as illustrated in the figure below. The figure tries to integrate figure 1 and 3 and should be read as how to integrate the ability to leverage similarity while still maintain the necessary flexibility by the use of different order decoupling points. The more a company move left towards Mass Production the more the processes and products will be standardized reducing the flexibility towards the market.

Insert Figure 10 about here

A prerequisite for leveraging similarity is an integration of the value chain. This implies that operating with Mass Customization presuppose the development of strategic partnerships and maybe even new types of companies. Here it is extremely interesting to follow the development of AEC companies, which due to their position in the value chain have the organisational capabilities for working with Mass Customization and system deliverances.

It is an essential pre-condition for these companies that they will be able to exploit the advantages of large volume by deliberately working towards developing modules which can be used in multiple projects. In other words, the use of modules is a strategy in order to achieve a larger volume of similar tasks.

This is however also a challenging process. By using modules the costs of the individual modules increase, while in relation to a number of other features, such as 
weight or use of materials, a module might seem over-dimensioned or not quite optimal. On the other hand the total costs are reduced, as the task of combining and adapting the individual parts into a complete product becomes considerably easier, and manufacturing becomes simpler and cheaper. In addition, there are a number of administrative costs connected with the introduction of a new variant in the company, as a product variant must be set up in the ERP system with, for example, lists of parts, lists of operations, prices etc., and this is associated with considerable costs. These types of cost are minimized by configuration of modularized products.

One of the biggest challenges in the use of modules is the individual member of the design staff may choose to sub-optimize and develop an individual variant/solution instead of using a standard module. The use of modules requires considerable discipline within the company and marked awareness of the division of costs between item costs and total costs.

Furthermore the effort of similarity does need to be related to the changing nature of the markets in the construction industry. This was illustrated in the case in which the installation shaft initially were targeted the booming market for apartments - a market which subsequently collapsed. As a result it has been difficult to identify possible projects for implementation of the installation shaft.

Achievements of scale effects are in other words difficult in construction industry due to the vulnerability due to the conjectures in market. The consequence is that system deliverances based on "bottom-up” generally are more robust. This is illustrated in the following figure showing how the installation shaft with minor changes can be implemented in other market segments as e.g. office buildings. 
Thereby the development of system deliverances is a possible platform for growth. This however requires:

1. a coordinated and coherent development around the system deliverance itself, its components and its internal and external modularity.

2. development of processes and configuration systems which make it possible to put together (configure) a system product matching the needs of the individual building project.

3. development of alliances between companies in the value chain aiming at integrating the value chain around the system deliverance.

These principles needs to be integrated in a coherent business model, involving a focused market strategy, development of module-based system products, sales and order handling based on the use of configuration systems, a production system with production for storage of standard modules and assembly to order of customerspecific products based on the use of standard modules, together with distribution, installation and after sales service based on the use of standard modules in the system products. Installation is carried out by specially trained installation staff. The use of standard modules makes the installation and after sales service much simpler and easier to carry out.

\section{CONCLUSION}

This paper has presented an analysis of the how new business models can be implemented in the construction industry by the use of system deliverances. The application of system deliveries is however demanding as it represents a fundamental shift in the existing design and production practices. 
More specifically the development of system deliveries requires:

1. an explicit market focus, enabling the achievement of economy of scale

2. a coordinated and coherent development around the system deliverance focusing on its internal and external modularity.

3. development of processes and configuration practices which make it possible to put together (configure) the product matching the needs of the individual building project.

4. development of alliances between companies in enabling value chain integration.

Findings from the development and production of the prefabricated installation shaft show that system deliveries represent a promising strategy for moving from red ocean competitive environment with the predominant cost+ business model, to a blue ocean situation in which the competition emerges in the constant pursue of value creation and cost reduction. On basis of that system deliverances represent a promising strategy in the future development and application of off-site manufacturing practices.

\section{REFERENCES}

Beim, A. Nielsen, J. og K. Vibæk (2009) Three Ways of Assembling a House, Centre of Industrialised Architecture by, Copenhagen

DS (2010), Dansk statistik Website: www.dst.dk visited 28. March 2010

Forza, C. and Salvador F. (2002), Managing for variety in the order acquisition and fulfillment process: The contribution of product configuration systems.”, International Journal of Production Economics, Vol.76, No.1, pp. 87-98.

Hansen, B.L. (2003) Development of Industrial Variant Specification Systems; Ph.D. dissertation, Technical University of Denmark 2003. 
Holti, R., Nicolini, D. and Smalley, M. (2002) "Final Report on the Building Down Barriers Action Research Initiative - Overview of the Building Down Barriers approach to Construction: what can be achieved and what kind of investment is involved?”, London: The Tavistock Institute.

Hvam, L. (2006) Mass customization in the electronics industry - based on modular products and product configuration. International Journal of Mass Customization, vol 1, no.4 2006, p. 410-426. ISSN 1742-4208 (Print), ISSN 1742-4216 (Online).

Hvam, L., Mortensen, N. H., and Riis, J., (2008), Product Customization, Springer, Berlin Johnson, M. W., Christensen, C. M., \& Kagermann, H. (2008). Reinventing Your Business Model. Harvard Business Review , 50-59.

Jørgensen, B. (2006). Integrating Lean Design and Lean Production: Priocesses and methods. Lyngby: Department of Civil Engineering DTU.

Kim, W. C. and R. Mauborgne (2004a). Blue Ocean Strategy. Harvard Business Review, 82(10), 76-84.

Kvale, S. (1996). Interviews An Introduction to Qualitative Research Interviewing, Sage Publications, 1996

Meyer, M.H. and Lehnerd, A.P. (1997), The Power of Product Platforms - Building Value and Cost Leadership, The Free Press, New York, NY

Mikkelsen, H., Beim, A., Hvam, L. og Tølle, M(2005) Systemleverancer i byggeriet - en udregning til arbejdsbrug.April 2005, Realdania. København

NCC (2008), Internal presentation of installation shaft, Copenhagen, 2008

Nicolini, D., Holti, R., and Smalley, M. (2001) “Integrating Project Activities: The Theory And Practice of Managing the Supply Chain Through Clusters”, Construction Management and Economics, Vol. 19, No.1, pp. 37-47. 
Pine, B. Joseph II (1993) Mass Customization - The New Frontier in Business Competition, Harvard Business School Press, Boston, Mass.

Salvador, F., Pablo Martin de Holan and Frank Piller; Cracking the code of Mass Customization; MIT Sloan Management review, Spring 2009, vol 50, no 3, p. 70-79.

Schöning, S. (2007). Kundengerecht und erfolgreich - Lean Product als zukunftsweisendes Produktkoncept. Frankfurt: WZL RWTHAACHEN.

Thuesen, C., Jensen, J. S., and Gottlieb, S. C, (2009), “Making the Long Tail Work Reflections the development of the Construction Industry the past 25 Years”, in Dainty, A. 25th Annual ARCOM Conference, 7-9 September 2009, Association of Researchers in Construction Management, Nottingham, UK, pp. 1111-20

Thuesen, C. (2010) Leveraging economy of scale across constrcution projects by iumplementing coordinated purchasing , CIB Salford 2010

Tseng Mitchell M. and Piller, Frank. T. eds(2003); The Customer Centric Enterprise Advances in Mass Customization and Personalization; Springer Verlag. ISBN 3-54002492-1.

Tseng, M.M.; Jiao, J. (2001), Mass Customization, in: Handbook of Industrial Engineering, Technology and Operation Management (3rd ed.), ISBN 0-471-33057-4

Vind, B. \& A. Thomassen, M. (2008) Byggeriets Innovation, Scanprint (Realdania) Womack, J. P. and Jones, D. T. (2003). Lean Thinking. Free Press.

Yin, R.K. (2002), Case Study Research. Design and Methods. Sage Publications. California. 